\title{
Loasaceae Lindl. no Estado do Rio de Janeiro, Brasil
}

\author{
Massimo G. Bovini ${ }^{1,2}$ e Luiz Carlos da Silva Giordano ${ }^{1}$
}

Recebido em 02/04/2004. Aceito em 03/09/2004

\begin{abstract}
RESUMO - (Loasaceae Lindl. no Estado do Rio de Janeiro, Brasil). São apresentadas três espécies de Loasaceae ocorrentes no Estado do Rio de Janeiro, Brasil: Loasa parviflora Schrad. é a espécie mais comum, enquanto Loasa uleana Urb. \& Gilg pode ser considerada ameaçada de extinção, na categoria criticamente em perigo, e Caiophora scabra (Miers.) Urb. \& Gilg foi registrada como nova ocorrência para o Estado. Neste trabalho foi localizado um provável isolectótipo de L. uleana que ainda teve seu fruto descrito e ilustrado pela primeira vez.
\end{abstract}

Palavras-chave: Loasaceae, taxonomia, fitogeografia, Rio de Janeiro

\begin{abstract}
Loasaceae Lindl. in the State of Rio de Janeiro, Brazil). Three species of Loasaceae from State of Rio de Janeiro, Brazil, are presented: Loasa parviflora Schrad. is the most frequent species, while L. uleana Urb. \& Gilg can be considered as critically endangered, and Caiophora scabra (Miers.) Urb. \& Gilg is a new occurrence to the state. A probable isolectotype of $L$. uleana was located, and the fruit of this species was described and illustrated for the first time.
\end{abstract}

Key words: Loasaceae, taxonomy, phytogeography, Rio de Janeiro

\section{Introdução}

A família Loasaceae possui cerca de 15 gêneros e 300 espécies distribuídas principalmente nas regiões tropicais e temperadas das Américas e, freqüentemente, é representada em áreas semi-áridas com grande diversificação no sudeste dos Estados Unidos, México e Chile; várias espécies, especialmente nos Andes, tem sido descobertas (Weigend 2004). Na flora brasileira a família está representada por seis gêneros, com aproximadamente 18 espécies (Barroso et al. 2002), em vários ambientes. A família subdivide-se em duas subfamílias: Loasoideae, compreendendo quatro tribos das quais três possuem representantes na flora brasileira, apresentando flores com pétalas profundamente cuculadas e estaminódios em grupos nas antessépalas; e Mentzelioideae, com representação restrita à América Central, apresentando flores com pétalas levemente aplanadas e membranáceas, estaminódios não em grupos nas antessépalas (Weigend 2004). O hábitat da família é diverso, possuindo indivíduos higrófilos e outros xerófilos; alguns preferem ambientes de baixada, próximos ou não do litoral, enquanto outros são próprios de altitudes, proporcionando a algumas espécies uma barreira geográfica para dispersão de seus representantes (Weigend 2004).

Como principal destaque para o tratamento sistemático da família toma-se o hábito dos espécimes, tricomas, filotaxia, inflorescências e a morfologia das pétalas, estaminódios, quando presentes, frutos e sementes.

No Brasil, o tratamento taxonômico de Loasaceae limita-se aos esforços de Vellozo $(1829 ; 1831)$ que descreveu e ilustrou três espécies para o Estado do Rio de Janeiro: Loasa urens Vell., atualmente sinonimizada por Weigend (1997) em Blumenbachia latifolia Cambess, indicada por Vellozo na localidade hoje conhecida como Serra dos Órgãos, e atualmente encontrada em herbários cariocas mencionada apenas como cultivada; Mentzelia aspera, considerada sinonímia de Caiophora eichleri em Weigend (1997), que acredita-se ser um sinônimo duvidoso, pois as características apresentadas na estampa da Flora Fluminensis mostram semelhanças que a aproximam de Caiophora scabra; e, finalmente, Mentzelia urens que Urban \& Gilg (1900) consideraram sinônimo de Loasa parviflora. Urban (1894) elaborou a monografia da família para o Brasil, reconhecendo 13 espécies, fornecendo chaves e ilustrações. Mais recentemente,

\footnotetext{
1 Instituto de Pesquisas Jardim Botânico do Rio de Janeiro, Rua Pacheco Leão 915, CEP 22460-030, Rio de Janeiro, RJ, Brasil

2 Autor para correspondência: nbovini@jbrj.gov.br
} 
Santos \& From-Trinta (1985), trataram as espécies ocorrentes no estado de Santa Catarina, e Pacheco (2002) descreveu as espécies do Estado de São Paulo.

Os resultados aqui apresentados contribuem para o conhecimento da flora do Estado do Rio de Janeiro, em especial a família Loasaceae, esclarecendo algumas questões nomenclaturais e fitogeográficas das espécies nativas.

\section{Material e métodos}

As descrições das espécies e a chave de identificação dos táxons são resultantes da análise morfológica das exsicatas pertencentes às coleções dos herbários GUA, R, RB, RBR, RFA, e RUSU (siglas de acordo com Holmgren et al. 1990) e de observações de campo, sendo a nomenclatura morfológica adotada com base em Rizzini (1977). As pranchas que ilustram este trabalho foram realizadas com auxílio de microscópio esteroscópio Willd e óptico Carl Zeiss, equipado com câmara clara, em diferentes escalas de aumento.

Os dados sobre os nomes populares, distribuição geográfica e hábitat foram obtidos conforme a consulta de literatura especializada, informações contidas em etiquetas das exsicatas e observações de campo e fornecidos após a descrição de cada táxon. A citação da obra de Vellozo está de acordo com Carauta (1969), as categorias de conservação segundo os critérios da IUCN (apud Carauta 2001) e para a classificação da vegetação adotou-se Rizzini (1997).

\section{Resultados}

\section{Loasaceae Lindl.}

Ervas ou subarbustos eretos, semi-escandentes ou trepadeiras volúveis, comumente com tricomas simples, ou apresentando nódulos agudos, gloquideados, glandulares unisseriados, fortemente silicificados e urticantes. Folhas sem estípulas, alternas ou opostas, simples; lâminas inteiras, pinatissectas ou lobadas, com ou sem hidatódios. Inflorescências em cimeiras, monocásios extra-axilares ou axilares e dicásios terminais. Flores actinomorfas, hermafroditas; cálice gamossépalo, com 5 lacínios elípticos, geralmente persistentes no fruto; corola com 5 pétalas livres, cuculadas ou ungüiculadas, alvas ou cremes. Estames numerosos, em grupos, opostos às pétalas, presença de estaminódios na série mais externa, opostos às sépalas e unidos às escamas nectaríferas alternandose com as pétalas; filetes filiformes; anteras biloculares, de ovais a oblongas; estaminódios com tricomas ou papilas, às vezes com rudimentos de antera. Escamas nectaríferas côncavas, com 3-7 nervuras, com ou sem apêndice filiforme no dorso. Ovário ínfero, turbinado ou fusiforme, 3-carpelar, unilocular, placentação parietal, muitos óvulos; estilete 0,2-0,3 cm compr.; estigma capitado. Frutos capsulares septicidas ou loculicidas, do tipo noz, fusiformes ou turbinados, às vezes com tricomas apresentando gloquídeos; sementes várias, aladas ou não aladas, pequenas, testa reticulada, embrião reto.

Chave para a identificação das espécies

1. Trepadeiras volúveis; ramos cilíndricos; flores com pétalas acentuadamente ungüiculadas, com máculas vermelhas; cápsulas estreitamente fusiformes, sementes aladas 1. Caiophora scabra

1. Ervas ou subarbustos eretos ou semi-escandentes; ramos angulosos; flores com pétalas ungüiculadas ou cuculadas; cápsulas turbinadas, sementes não aladas.

2. Ervas ou subarbustos eretos; folhas alternas; pecíolo até 8,0 cm compr.; lâmina lobada ou fendida; pétalas cuculadas. 2. Loasa parviflora

2. Ervas semi-escandentes; folhas opostas; pecíolo até 12,0 cm compr.; lâmina inteira; pétalas ungüiculadas 3. Loasa uleana

1. Caiophora scabra (Miers.) Urb. \& Gilg in Engl. \& Prantl, Nat. Pflanzenfam. 3 (6a): 121. 1894.

Figura $1 \mathrm{~J}, 3$.

Trepadeiras volúveis. Ramos hirsutos, tricomas simples. Folhas opostas; pecíolo até 5,0 cm compr., lâmina ovado-triangular, 3-5 lobada, até 9,0 cm compr. × 10,0 cm larg., base auriculada, ápice agudo, margem serreada, hirsutas em ambas as faces, tricomas simples com coroa de células ao redor, nervação craspedódroma. Inflorescências monocásios axilares, bractéolas curto-pecioladas, oval-triangulares, até 2,0 cm compr. $\times$ 1,5 cm larg.; pedúnculo até 9,5 cm compr. Flores com hipanto estreito-turbinado, hirsuto; cálice apresentando lacínios ca. 0,8 cm compr. × 0,2 cm larg., 
membranáceos, hirsuto, tricomas gloquideados; corola ca. 1,0 cm diâm., pétalas acentuadamente ungüiculadas, ca. 0,5 cm compr., alvas ou cremes, com máculas vermelhas. Estames vários, escamas nectaríferas com 2 estaminódios e 3 apêndices filiformes no dorso. Ovário fusiforme; estilete $0,2 \mathrm{~cm}$ compr. Cápsulas estreitamente fusiformes, até $3,0 \mathrm{~cm}$ compr. $\times 1 \mathrm{~cm}$ larg., hirsutas, gloquideadas com vestígios dos lacínios do cálice; sementes ca. 0,1 cm compr., aladas.

Material examinado: BRASIL. Itatiaia: Parque Nacional, Maromba, 15/IX/1937, fl., fr., J.G. Kuhlmann s.n. (RB 21419); idem, trilha do Hotel Simon para os Três Picos, 7/XII/1995, fr., J.M.A. Braga 3081 et al. (RB).

Distribuição geográfica: segundo Santos \& Fromm Trinta (1985), a espécie encontra-se representada na Floresta Pluvial Atlântica dos Estados de São Paulo, Paraná e Santa Catarina, em altitudes entre 50 e $600 \mathrm{~m}$, em formações florestais de baixo a alto-montana. No presente artigo registrase, pela primeira vez, a ocorrência para o Estado do Rio de Janeiro, ampliando a área de distribuição no sudeste do Brasil.

Comentários: C. scabra caracteriza-se pela lâmina foliar ovado-triangular, 3-5 lobada e, principalmente, por suas pétalas apresentando-se alvas com máculas vermelhas. Seus indivíduos são conhecidos popularmente como cansação. Espécie muito próxima de Caiophora eichleri (Urb.) Urb., motivo pelo qual até hoje são confundidas, sendo esta última com flores e frutos de dimensões menores e representada apenas no sul do Brasil.

2. Loasa parviflora Schrad., Pl. Rar. Bras. ined. in DC. Prod. 3: 342. 1828.

Figura 1 A-I, 3.

Ervas ou subarbustos eretos até 1,0 m alt. Ramos hirsutos, tricomas simples, ou apresentando nódulos agudos e glandulares. Folhas alternas; pecíolo até 8,0 cm compr., lâmina lobada ou fendida, até $16,5 \mathrm{~cm}$ compr. $\times 15,0 \mathrm{~cm}$ larg., base reniforme, às vezes assimétrica, ápice agudo, margem crenada, hirsuta em ambas as faces, tricomas glandulares; nervação broquidódroma. Inflorescências extra-axilares, monocásios, bractéolas curto-pecioladas, ovaltriangulares, até $1,0 \mathrm{~cm}$ compr. $\times 0,5 \mathrm{~cm}$ larg.; pedúnculo ca. $2,0 \mathrm{~cm}$, hirsuto, tricomas longos. Flores com cálice apresentando lacínios membranáceos ca. $0,5 \mathrm{~cm}$ compr. $\times 0,2 \mathrm{~cm}$ larg., hirsuto, tricomas gloquideados; corola ca. 1,0 cm diâm., pétalas cuculadas, ca. 0,5 cm compr., alvas. Estames vários; escamas nectaríferas com 2 estaminódios e 3 apêndices filiformes no dorso. Ovário turbinado; estilete $0,2 \mathrm{~cm}$ compr. Cápsulas turbinadas, até 1,0 cm compr. × 1,0 cm larg., hirsutas, gloquideadas, lacínios do cálice persistentes e senescentes, са. 0,2 cm compr.; sementes com menos de $0,1 \mathrm{~cm}$ compr., elípticas.

Material examinado: BRASIL. Itatiaia: Parque Nacional, Maromba, picada nova, 20/II/1945, fl., A.C. Brade 17485 (RB). Mangaratiba: Reserva Rio das Pedras, trilha das Bromélias, proximidades do Poço do Rio Grande, 17/VIII/1996, fl., fr., J.M.A. Braga 3447 (RUSU). Maricá: Picada da Represa de Maricá, V/1943, fl., J. Vidal s.n. (R 38991). Niterói: Parque da Cidade, Morro da Viração, 26/IX/1991, fl., fr., M.C. Vianna et al. 2078 (GUA). Petrópolis: Raiz da Serra, 1876, fl., fr., Schwacke s.n. (R 90356). Rio de Janeiro: Arquipélago de Cagarras, Ilha Redonda, 6/XII/1981, fl., R. Ribeiro 204 (GUA); Copacabana, s.d., fl., C. Diogo 137 (R); Corcovado, s.d., fl., Glaziou 137 (R); idem, 9/I/1862, fl., Glaziou 193 (R); estrada da Vista Chinesa, 9/III/1989, fl., fr., J. Santos 41 (RBR); estrada de Santa Cruz, 14/V/1916, fl., A. Lutz 1018 (R); Furnas da Tijuca, 16/IV/1958, fl., fr., E. Pereira et al. 3640 (RB); Jacarepaguá, Pau-da-Fome, 11/XII/1980, fr., M.B. Casari et al. 388 (GUA); idem, idem, trilha para o Pico da Pedra Branca, 23/V/1993, fl., fr., J.M.A. Braga 377 \& R. Neves (RUSU); mata da Urca, 1965, fl., fr., V.V. Wilberg s.n. (RFA 7796); matas/encosta do Jardim Botânico, 20/III/1942, fl., fr., E. Pereira s.n. (R 90385); idem, Pedra do Marinheiro, 24/V/1979, fl., fr., M. dos Santos et al. 30 (GUA, RB); idem, idem, 7/VI/1986, fl., fr., L.C. Giordano et al. 79 (RB); idem, idem, 25/I/1989, fl., L.C. Giordano et al. 553 (RB); idem, idem, 4/VIII/1993, fl., fr., $R$. Marquete et al. 1172 (RB); morro da Gávea, 2/XII/1948, fl., fr., Palácios et al. 2803 (R); morro do Leme, 7/V/1988, fr., Carauta et al. 5591 (GUA); Pão-de-Açúcar, estrada para o costão, 26/VIII/1979, fl., J.P.P. Carauta 3162 \& M.B. Casari 41 (GUA, RB); praia de Sernambetiba, s.d., fl., fr., L.B. Smith et al. 6336 (R); praia Vermelha, VI/1913, fl., F.C. Hoehne "21" (R 90387); Recreio dos Bandeirantes, Prainha, 3/VI/1988, fl., fr., L.C. Giordano et al. 412 (RB); idem, idem, junto à Pedra da Boa Vista, 10/XII/1998, fl., fr., B. Longo 4 \& J.M.A. Braga (RB); idem, idem, morro da Boa Vista, 6/VI/1996, fl., fr., M.G. Bovini 998 \& J.M.A. Braga (RUSU); idem, idem, 7/XII/2002, fl., fr., M.G. Bovini 2260 \& K. De Toni (RB); Realengo, IX/1933, fl., C.V. Freire 


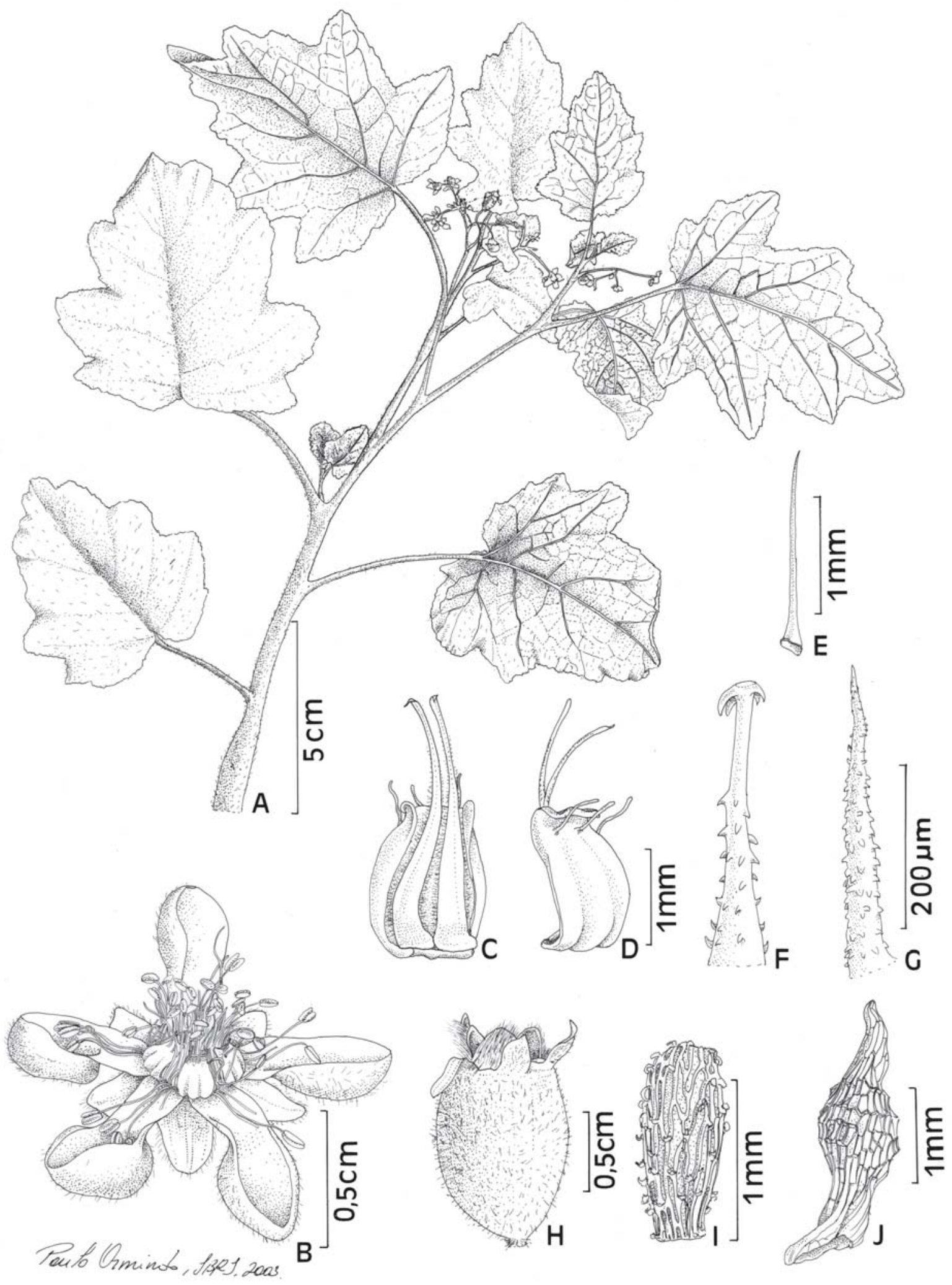

Figura 1. Loasa parviflora Schrad. (A-I, M.G. Bovini 2260). A. Parte do ramo; B. Flor. C-D. Escamas nectaríferas com estaminódios e apêndices dorsais. E-G. Tricomas (simples, gloquideado e ápice agudo, haste com nódulos agudos, respectivamente). H. Fruto. I. Semente. Caiophora scabra (Miers.) Urb. \& Gilg (J, J.M.A. Braga 3081). J. Semente alada. 
380 (R); restinga da Gávea, 1937, fl., fr., J.G. Kuhlmann s.n. (RB 1048); restinga de Grumari, 8/III/1935, fl., fr., C.V. Freire 602 \& alii (R); Sacopan, morro da Saudade, 27/V/1943, fl., fr., Guerra \& Octavio s.n. (RB 48125); serra da Bica, 26/VIII/1886, fl., Schwacke s.n. (R 90368); Tijuca, 25/V/1926, fl., fr., B. Lutz s.n. (R 15682); serra da Tijuca, IV/1929, fl., fr., A.C. Brade 10466 (R); serra do Andaraí, 19/XII/1946, fl., L.E. de Mello Filho 534 (R); Trapicheiros, Engenho Velho, 9/III/1957, fl., fr., V. Stawiarski s.n. (R 198806); Vargem Grande, estrada da Boca do Mato, caminho para a represa do Camorim, 25/VIII/1980, fl., fr., E.S.F. da Rocha 161 (GUA). Local desconhecido, "voyage 18161821”, fl., fr., A. de Saint-Hilaire “392” (R 90395); idem, 1886, fl., coletor desconhecido (R 90360); idem, 12/XI/1945, fl., P. Occhioni 518 (RB); idem, “Cachoeira”, 1878, fl., Siqueira s.n. (R 90381).

Distribuição geográfica: esta espécie encontra-se representada em Restinga ou em Floresta Pluvial Atlântica, tanto em locais de baixada quanto de altitude, nos Estados da Bahia, Minas Gerais, Espírito Santo, Rio de Janeiro e São Paulo.

Comentários: o hábito ereto, as folhas alternas, a lâmina foliar lobada ou fendida, e a presença de tricomas glandulares nos ramos e nas folhas causando sensação "pegajosa" e urticante ao toque, delimitam esta espécie. Possui o maior número de representantes da família no Estado do Rio de Janeiro, os quais são conhecidos popularmente como cansação.

3. Loasa uleana Urb. \& Gilg, Nova Acta Acad. Caes. Leopold. - Carol. German. Nat. Cur. 76 (1): 255. 1900. Figura 2 A-E, 3.

Ervas semi-escandentes. Ramos hirsutos, tricomas simples, ou apresentando nódulos agudos e gloquideados. Folhas opostas; pecíolos até $12,0 \mathrm{~cm}$ compr., lâmina inteira, ovada, até $21,0 \mathrm{~cm}$ compr. × $16,5 \mathrm{~cm}$ larg., base obtusa a cordiforme, ápice agudo, margem irregularmente serreada, com hidatódios, hirsutas em ambas as faces, tricomas gloquideados na face dorsal e simples na face ventral, nervação craspedódroma. Inflorescências dicásios terminais; bractéolas curto-pecioladas, oval-triangulares, até $1,5 \mathrm{~cm}$ compr. $\times 1,0 \mathrm{~cm}$ larg., pedúnculo até $5,5 \mathrm{~cm}$ compr., tricomas simples, longos e gloquídeos. Flores com cálice apresentando lacínios membranáceos 0,2 cm compr. $\times 0,1 \mathrm{~cm}$ larg., hirsuto, tricomas simples e raros gloquídeos; corola ca. 1,0 cm diâm., pétalas ungüiculadas, са. 0,4 cm compr., alvas. Estames vários, escamas nectaríferas com 2 estaminódios e 3 apêndices filiformes no dorso. Ovário turbinado, gloquideado; estilete com ca. 0,3 cm compr. Cápsula turbinada, até $1,0 \mathrm{~cm}$ compr. × 0,6 cm larg., gloquideada, lacínios do cálice persistentes e senescentes, ca. 0,2 cm compr.; sementes com menos de 0,1 cm compr., elípticas.

Material examinado: BRASIL. Itatiaia: serra do Itatiaia, 1500 m s.m., Ule “617”, 26-12-1895 (R! 90367, isolectótipo aqui localizado); Lote 46, 20/III/1947, fl., fr., P. Occhioni 965 (RFA); Parque Nacional, estrada do Maromba, III/1948, fl., fr., A.P. Duarte 1195 (RB); idem, à margem do rio, 26/V/1902, fr., coletor desconhecido (R 90366); Maromba, próxima a cachoeira Véu da Noiva, 7/III/2003, fl., fr., M.G. Bovini 2267 \& K. De Toni (RB).

Distribuição geográfica: espécie endêmica do Estado do Rio de Janeiro, registrada apenas no Parque Nacional de Itatiaia.

Comentários: além da folha oposta, a lâmina foliar ovada e a inflorescência em dicásio caracterizam a espécie. A presença de hidatódios na margem foliar é marcante para a espécie, tanto em material vivo, como herborizado. Pode-se dizer que L. uleana é considerada ameaçada de extinção na categoria criticamente em perigo. Até o presente artigo, o último registro de coleta de L. uleana foi em 1948, por A.P. Duarte 1195. Weigend (1997) cita somente um material existente para a espécie, o lectótipo Ule 3713, documentado no herbário HBG, mas este material citado possui a mesma data de coleta e localidade do material de Ule “617” do herbário do Museu Nacional (R 90367). Como os autores do presente trabalho não examinaram o material do HBG, e considerando que uma parte da coleção de Ule encontra-se no herbário do Museu Nacional, supõe-se que o exemplar Ule “617” (R 90367) seja uma duplicata e, por isso, provavelmente um isolectótipo. Agora com mais espécimes encontrados da espécie, e principalmente com o fruto maduro descrito e ilustrado pela primeira vez neste artigo, uma revisão do gênero poderá esclarecer sua posição sistemática, pois a série Corymbosae nomeada por Urban \& Gilg (1900) ainda não está bem definida. Essa série possui esta única espécie, descrita com base apenas no material de Ule 3713. Todos os membros de Loasa brasileiros possuem folhas alternas e inflorescência em monocásio e apenas as espécies andinas possuem folhas opostas e alguns com inflorescência em dicásio como a espécie em questão. 


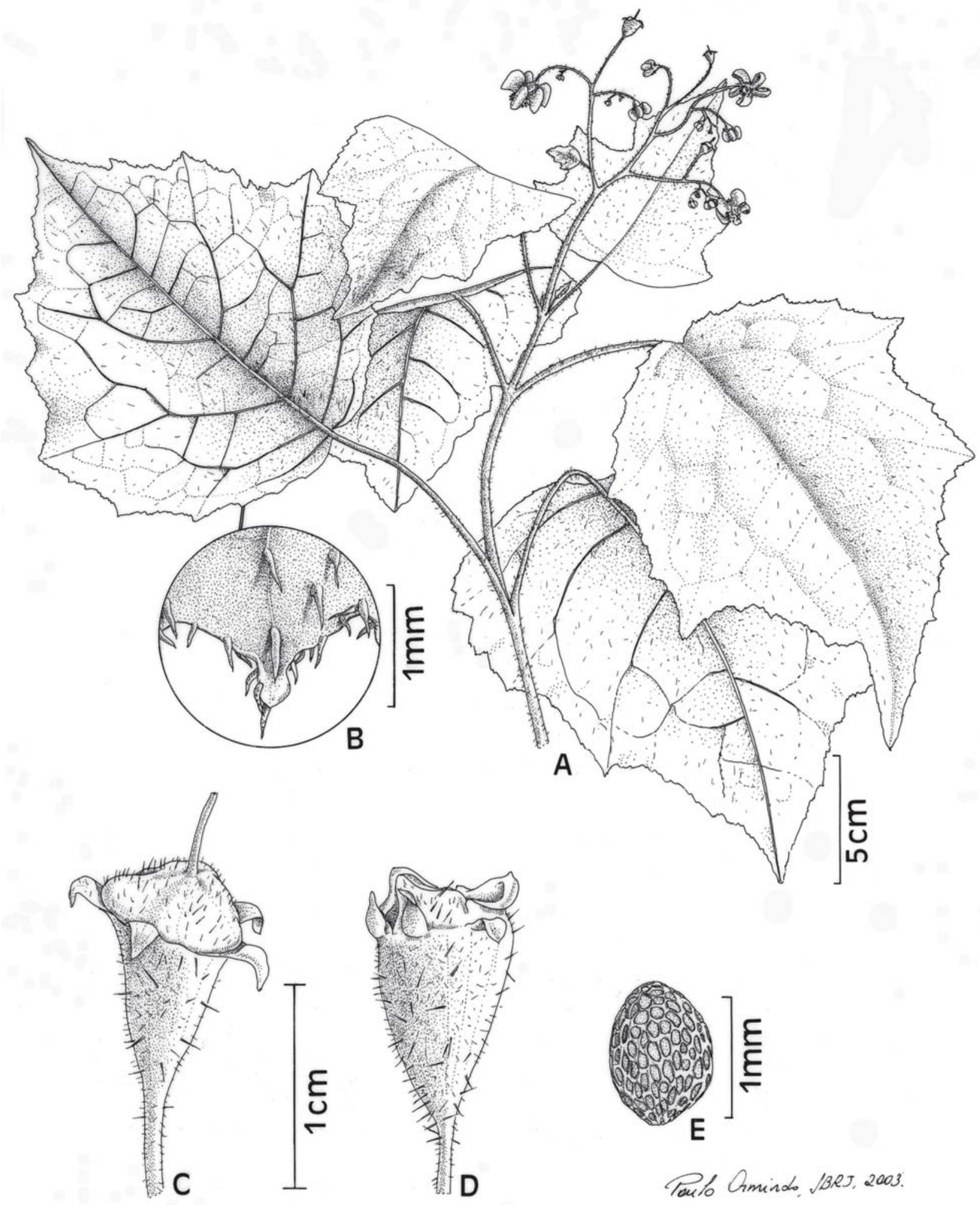

Figura 2. Loasa uleana Urb. \& Gilg (A-D, M.G.Bovini 2267). A. Parte do ramo. B. Hidatódio. C. Fruto imaturo. D. Fruto maduro. E. Semente. 


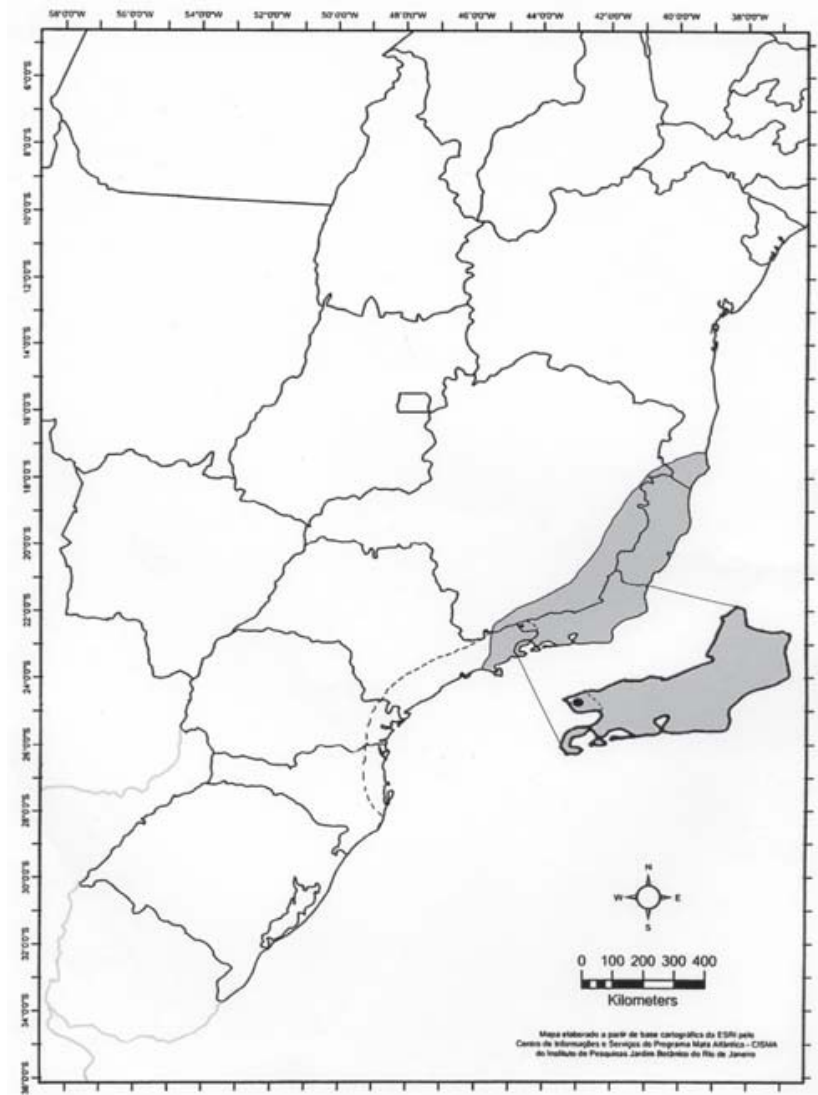

Figura 3. Distribuição geográfica: • Loasa uleana Urb. \& Gilg; — Loasa parviflora Schrad; --- Caiophora scabra (Miers.) Urb. \& Gilg.

\section{Agradecimentos}

Aos curadores dos herbários citados, pelo empréstimo de material para análise; aos pesquisadores João Marcelo A. Braga, pelo esclarecimento da obra de Velloso, e Sebastião José da S. Neto, pelas observações de campo de L. uleana; a Rosemberg Silva, d Programa Mata Atlântica, pela confecção do mapa.

\section{Referências bibliográficas}

Barroso, G.M.; Guimarães, E.F.; Ichaso, C.L.F.; Costa, C.G. \& Peixoto, A.L. 2002. Loasaceae. Pp. 227-229. In: Sistemática de Angiospermas do Brasil. v.1. 2. ed., São Paulo, Editora UFV.

Carauta, J.P.P. 1969. A data efetiva da publicação da "Flora Fluminensis”. Vellozia 7: 26-33.

Carauta, J.P.P. 2001. Biota em risco de extinção II. Exemplos de Ficus (Moraceae). Albertoa (série Urticineae) 6: 37-42.

Holmgren, P.K.; Holmgren, N.H. \& Barnett, L.C. 1990. Index Herbariorum, part 1: the herbaria of the world. New York, New York Botanical Garden.

Pacheco, A.M.F. 2002. Loasaceae. Pp. 159-161. In: M.G.L. Wanderley, G.J. Sheperd \& A.M. Giulietti (eds.). Flora Fanerogâmica do Estado de São Paulo. v.2. São Paulo, Editora Hucitec.

Rizzini, C.T. 1977. Sistematização terminológica da folha. Rodriguésia 42: 103-125.

Rizzini, C.T. 1997. Tratado de Fitogeografia do Brasil. Aspectos ecológicos, sociológicos e florísticos. 2. ed. Rio de Janeiro, Âmbito Cultural.

Santos, E. \& Fromm-Trinta, E. 1985. Loasáceas. Pp. 3-20. In: P.R. Reitz (ed.). Flora Ilustrada Catarinense. Itajaí, Herbário Barbosa Rodrigues.

Urban, I.P. 1894. Loasaceae. Pp. 197-224. In: C.F.P. von Martius; A.W. Eichler \& I.P. Urban (eds.). Flora Brasiliensis13(3). Leipzig, München, Wien.

Urban, I. \& Gilg, W. 1900. Monografia Loasacearum. Nova Acta Acad. Caes. Leop. Carol. German. Nat. Cur. 76: 1-368.

Vellozo, J.M.C. 1829 (1825). Flora Fluminensis. Rio de Janeiro, Typographia Nationali.

Vellozo, J.M.C. 1831 (1827). Florae Fluminensis Icones. Paris, Litohgr. Senefelder.

Weigend, M. 1997. Loasoideae in Eastern South America and Hispaniola: names, types and a key. Sendtnera 4: 207-220.

Weigend, M. 2004. The Loasaceae web page. Disponível em: <http://www.nybg.org/bsci/res/loas/>. Acesso em: 28/junho/2004. 